\title{
EDITORIAL
}

\section{CONSIDERACIONES SOBRE EL PLAN DECENAL DE DESARROLLO DE LA EDUCACIÓN}

\author{
Ramsés Hakim Murad \\ Vicerrector de Investigaciones
}

En varias ocasiones, se ha planteado que el Plan de Desarrollo para la educación, la salud y la vivienda debe ser un mandato constitucional, decenal o a veinte años. Como no se cuenta con una reforma en nuestra carta magna que asegure estas propuestas, mi opinión está de acuerdo con el Plan Decenal de Educación que está trazando este gobierno, así no tenga fuerza constitucional. Esta decisión, ligada a la permanencia del Ministro, por lo menos de cinco años, hace creíble el esfuerzo y los proyectos correspondientes. No hay que olvidar que en los últimos 100 años hemos contado con 120 ministros de educación, la mayoría de los cuales su contacto con los problemas educativos, se iniciaba al posesionarse del cargo. Quiero manifestar no estar en contra de políticos para esta ocupación; lo que considero es que tenemos educadores quienes comprenden muy bien la administración educativa, que podrían ser excelentes dirigentes con más posibilidades de acertar positivamente en su gestión que la mayoría de los políticos lanzados a ocupar un cargo, para el cual carecen del conocimiento pertinente.

La educación es una de las prioridades estratégicas para el progreso y el desarrollo, es la esencia de la cultura y del desarrollo de una nación.

En la preparación del Plan Decenal, se proponen algunos planteamientos enfocados en un sistema de calidad con equidad real para todos los colombianos. Mi propuesta es costosa y significa que el gobierno se dedique a buscar la paz por todos los medios y así liberar el $70 \%$ del gasto del Ministerio de Defensa y trasladarlo al sector social y, fundamentalmente, al sistema educativo. La guerra es muy costosa y no es ganable por ninguno de los contendientes, o cies que 50 años de lucha no dicen nada? La paz debe ser un propósito nacional, donde los partidos políticos, el gobierno, la guerrilla, el sector privado y la sociedad en general, por intermedio de sus organizaciones no gubernamentales, deben participar, apoyados por la comunidad internacional. Poner fin al desangre fraticida y al gasto en armamento y regresar a ser una sociedad civilista y democrática, todo esto para ser justos con la población mayoritaria del país: la gente pobre. Hacer un gran esfuerzo económico para la cobertura en vivienda, la garantía de la salud y sobretodo, para el acceso a la educación de calidad.

¿Qué entiendo yo como educación básica con calidad?

Ofrecer, tanto en la ciudad como en el campo, la misma calidad que brindan los mejores colegios privados, representada por infraestructura física: aulas cómodas, con dotación de medios audiovisuales; con canchas deportivas; con servicios apropiados y suficientes; con una biblioteca y con conexión a Internet y, laboratorios de ciencias dotados. Y lo más importante, contar con maestros preparados y actualizados pedagógica y metodológicamente, con formación académica competente en la asignatura que enseñan.

Así, se podría emprender un viraje hacia una formación de calidad y de equidad. En la edad temprana iniciar la educación en las artes: música, escultura, pintura, teatro e historia del arte, acompañada con un aula para realizar presentaciones. La educación básica debe proporcionar las herramientas para el desarrollo y la formación de científicos para el futuro investigativo, así como de ciudadanos amantes de las artes y la democracia.

La educación media en el sector público debe contar con una mayor capacidad de atención. Pasar del millón y algo de alumnos a por lo menos el $50 \%$ de la cobertura total, en un plazo de 10 años y al $80 \%$, en 20 años, es una meta prioritaria. Como es evidente, la calidad y la infraestructura deben ser similares a la educación privada de alta calidad. 
¿Qué significa este planteamiento?

Colegios públicos con una excelente infraestructura: aulas presenciales y virtuales, salones de informática dotados, biblioteca en ciencias y con un buen contenido cultural, en literatura, en teatro, en historia del desarrollo de la cultura universal y nacional y, por supuesto, bases de informática y electrónica, de acceso inmediato. Estos colegios deben poseer, además, para el desarrollo sicomotriz, campos deportivos, gimnasio, aula-teatro y sala de música; laboratorios con medidas de bioseguridad. De igual manera, contar con un profesorado de alta formación pedagógica y metodológica, así como preparación académica en docencia, ya sea ciencias naturales y/o sociales y, en el área de las bellas artes y en literatura.

El crecimiento del número de estudiantes de educación media en el sector público debe ir acompañado de una diversificación en la formación. Se vislumbra un $30 \%$ de colegios de tipo tecnológico preparando a los estudiantes para labores técnicas, dentro de la formación del bachiller. Existe una amplia gama de oficios a ofrecer en la medida en que el sector productivo y de servicios así lo demande. También, se debe orientar al personal docente a prestar sus servicios en forma práctica, creando empresas que ofrezcan estas ocupaciones. Este bachillerato técnico debe estar coordinado con la formación de la educación superior.

Respecto a la educación superior hay algunos frentes a estudiar. La Universidad pública y dentro de ella las más desarrolladas académicamente deben continuar con el crecimiento hasta llegar a conquistar, en los próximos diez años, el $60 \%$ de la matrícula total. Mis argumentos son: la sub-utilización de la infraestructura locativa y de laboratorios y el alto número de profesores de tiempo completo, quienes solo trabajan de 10 a 15 horas semanales, con una dedicación de tiempo completo real de solo entre el 5 y $15 \%$ dedicados a la investigación. Hay que hacer más eficiente a la universidad pública. Revisar la nómina y hacer que los profesores se dediquen plenamente al campo académico, científico y tecnológico. Hace más de diez años planteé a rectores de universidades públicas utilizar la infraestructura y el profesorado para la formación de alta calidad en las tecnologías duras, pues el sector privado solo parece dedicarse a tecnologías blandas, por falta de infraestructura. Por ello es necesario, para este Plan Decenal, una exhaustiva revisión de la nómina de los entes públicos, política que complementaría el esfuerzo del gobierno en materia de formación tecnológica.

El costo de la matrícula, se debe manejar por escalas basadas en los estratos socio-económicos. Esta formación, altamente costosa, financia a los estratos 3 , 4, 5 y 6 porque en la actualidad, los estratos 1 y 2, los más numerosos de la población, técnicamente no terminan la educación media y son minoría en la educación superior. El valor agregado de la matrícula debe ser esencialmente repartido: $80 \%$ para mejorar la infraestructura y el $20 \%$ restante para contratar profesores.

Se debe en la educación superior pública promover los doctorados en ciencias y tecnologías, como estrategia para mejorar la creación de conocimiento, optimizar el desarrollo industrial y empresarial y lograr patentes en el área técnica y tecnológica. Los doctorados, se deben complementar con maestrías de tipo investigativo y de profundización profesional, incluyendo las actuales especializaciones clínicas y las sub-especialidades médicas o quirúrgicas llevadas a doctorados profesionalizantes.

Los posgrados, las maestrías y los doctorados deben ser financiados por el Estado, por la empresa privada y por fundaciones de tipo educativo. Son estratégicos para el desarrollo científico y tecnológico y, deben ser subsidiados a través de fondos, tal como ocurre en el mundo desarrollado. La ciencia y la tecnología benefician al país y no a los particulares; de allí el esfuerzo por parte del Estado y los empresarios. Los actuales estudiantes en especializaciones hospitalarias también deben ser subsidiados. Hoy están siendo explotados laboralmente por las IPS y económicamente por pago de matrículas exageradas que se reparte entre el hospital y la universidad. Esto amerita una corrección pronta por parte de los ministerios de educación y de la protección social. Los residentes hospitalarios en formación prestan un gran servicio a la buena marcha hospitalaria la cual se debe remunerar.

A la universidad privada, se le debe permitir el lucro y no exigirles ser instituciones sin ánimo de lucro. Un buen número de ellas son organizaciones manejadas para beneficio de una familia a través de la matrícula. De esta forma progresarían más claramente como empresas y, pagarían impuestos y se les aplicaría un sistema de inspección y vigilancia doble: académico y económico. 